\title{
TITLE:
}

\section{Influence of oxalic acid formed on the degradation of phenol by Fenton reagent.}

$\operatorname{AUTHOR}(S)$ :

Nakagawa, Hiroyuki; Yamaguchi, Emi

\section{CITATION:}

Nakagawa, Hiroyuki ...[et al]. Influence of oxalic acid formed on the degradation of phenol by Fenton reagent.. Chemosphere 2012, 88(2): 183-187

ISSUE DATE:

2012-06

URL:

http://hdl.handle.net/2433/155818

RIGHT:

(C) 2012 Elsevier Ltd. 
3 Influence of oxalic acid formed on the degradation of phenol by Fenton reagent

11 * Corresponding author. Tel.: +81 75753 7715; fax +81 757537710 .

12 E-mail address: hiroyuki@cheme.kyoto-u.ac.jp (H. Nakagawa). 
19 ABSTRACT

The objective of this work is to examine the influence of oxalic acid formed

21 on the degradation of phenol by Fenton reagent. Oxalic acid formed at initial stage

within 30 min significantly suppresses the reduction of ferric ion, thus terminating

degradation reaction. The yield of oxalic acid is dependent on the amount of ferrous

ion dosed since the minimal amount of oxalic acid is formed after the degradation

reaction terminates. Mineralization of phenol by Fenton reagent stagnates after 120

min under the conditions used in this study. The reason why the mineralization

stagnated can be assumed to be following two mechanisms other than the depletion of

$\mathrm{H}_{2} \mathrm{O}_{2}$. In the case where a small amount of ferrous ions is dosed, the reduction of ferric

ions is minimal by oxalic acid formed. In the case where a large amount of ferrous ions

is dosed, the amount of degradable organic compounds is insufficient owing to preferential conversion to oxalic acid. The mineralization can be enhanced by the intermittent dosing of ferrous ions, which facilitates the suppression of oxalic acid formation during the degradation by Fenton reagent. 


\section{Introduction}

Treatment of wastewater containing organic pollutants has been of great

concern all over the world. Advanced oxidation processes (AOPs) have great potential

in treating wastewater containing organic pollutants at room temperature, and a number

of AOPs have been proposed. Among them, Fenton oxidation, in which wastewater is

treated with Fenton reagent (ferrous salt $+\mathrm{H}_{2} \mathrm{O}_{2}$ ), is an attractive oxidative process for

wastewater treatment because iron is a very abundant and non-toxic element and

hydrogen peroxide is easy to handle and environmentally safe (Andreozzi et al., 1999).

Therefore, it has been adopted as the process for treating various industrial wastes

(Wadley and Waite, 2004; Bautista et al., 2008).

involving Fenton reagent (Reaction (1)) attacks organic compounds, enabling these compounds to be degraded through oxidation (Harber and Weiss, 1934).

$$
\mathrm{Fe}(\mathrm{II})+\mathrm{H}_{2} \mathrm{O}_{2} \rightarrow \mathrm{Fe}(\mathrm{III})+\mathrm{HO} \cdot+\mathrm{OH}^{-}
$$

51 The regeneration of $\mathrm{Fe}(\mathrm{III})$ to $\mathrm{Fe}(\mathrm{II})$ through the reduction by $\mathrm{H}_{2} \mathrm{O}_{2}$ or $\mathrm{HO}_{2}$. formed

52 from $\mathrm{H}_{2} \mathrm{O}_{2}$ also occurs in this reaction system (Barb et al., 1951a, 1951b; Walling, 1975).

53 Therefore, as long as $\mathrm{H}_{2} \mathrm{O}_{2}$ is available, the redox cycle of iron ions is basically

54 continuous between $\mathrm{Fe}(\mathrm{II})$ and $\mathrm{Fe}(\mathrm{III})$, thus forming a hydroxyl radical. It is essential to 
55 promote this cycle in order to degrade organic compounds efficiently. It is well known

56 that with the Fenton process, this mineralization is very likely to stagnate before it is

57 complete. Therefore, the Fenton process has been proposed primarily as a pretreatment

to reduce the effluent toxicity to safe levels and to improve biodegradability for further

biological treatment (Chamarro et al., 2001; Lopez et al., 2004). In order to enhance the analyze the intermediate products that remain in the water treated with Fenton reagent and to examine the reasons why the mineralization stagnates. redox cycle of iron (Tamagaki et al., 1989a, 1989b; Chen and Pignatello, 1997). Mijangos et al. (2006) examined the changes in solution color during treatment and reported that the observed color was due to an intermediate product of the main reaction, such as benzoquinones or benzene rings coordinated with ferric ions. Kang et al. (2002) focused on the interaction of the organic intermediates with the Fe species. Zimbron and Reardon (2009) suggested that organic intermediates formed during pentachlorophenol degradation by Fenton reagent have a $\mathrm{HO} \cdot$ scavenging effect from the kinetic model calculation. Among these intermediate products, we focus on the relatively stable organic acids, which may remain after the treatment, in order to enhance the degree of 
73 mineralization. Acetic, maleic, malonic, and oxalic acids are known to be poorly

degradable by Fenton reagent (Bigda, 1995). In particular, oxalic acid can deactivate Fe ion activity by the strong coordination with Fe(III) (Sun and Pignatello, 1992, 1993;

Kwon et al., 1999). Zazo et al. (2005) reported that oxalic acid reached a high relative

concentration among organic acids formed during phenol degradation by Fenton reagent,

although its formation rate was lower than that of other acids. They also reported that

the concentration of oxalic acid increased at increasing ferrous ion dose (Zazo et al., 2007).

In this study, we focus on the formation of organic acids, especially oxalic acid, and discuss its influence on the degradation of phenol by Fenton reagent. We examine the effect of the reaction conditions on the formation behavior of oxalic acid. We discuss the influence of oxalic acid on the consumption of $\mathrm{H}_{2} \mathrm{O}_{2}$ and the mineralization behavior under the conditions used in this study for the view point of iron cycle. Finally, we propose a method for enhancing the degree of mineralization using the same amount of Fenton reagent.

\section{Experimental methods}

90

\subsection{Chemicals}


$92(>99 \%)$ was used as the organic pollutant in this study. It was used without any other

93 purification. A $1000 \mathrm{mg} \mathrm{L}^{-1}$ phenol solution was prepared using distilled water and was

94 stored in a glass bottle. Solutions of $\mathrm{FeSO}_{4} \cdot 6 \mathrm{H}_{2} \mathrm{O}$ and $\mathrm{Fe}_{2}\left(\mathrm{SO}_{4}\right)_{3} \cdot 9 \mathrm{H}_{2} \mathrm{O}(0.25 \mathrm{M}$ each)

95 were prepared and used as ferrous and ferric ion sources, respectively.

96

97

98

99

100

101

102

\subsection{Procedure}

The reactor was a $300 \mathrm{~mL}$ glass beaker with a magnetic stirrer. We prepared $250 \mathrm{~mL}$ of a $100 \mathrm{mg} \mathrm{L}^{-1}$ phenol solution, adjusted the $\mathrm{pH}$ to 3.0 using $0.1 \mathrm{M} \mathrm{H}_{2} \mathrm{SO}_{4}$, and dosed a designated amount of $\mathrm{H}_{2} \mathrm{O}_{2}$ solution (15 wt $\%$ ). We then dosed a designated amount of $0.25 \mathrm{M} \mathrm{FeSO}_{4}$ to initiate the reaction. The experiment was carried out at room temperature $\left(23 \pm 2{ }^{\circ} \mathrm{C}\right)$ in a dark room to avoid the effect of light. The initial concentrations of ferrous ion, $C_{\mathrm{Fe}(\mathrm{II}), 0}$, and $\mathrm{H}_{2} \mathrm{O}_{2}, C_{\mathrm{H} 2 \mathrm{O} 2,0}$, in a reactor were varied from 0.1 to $1.5 \mathrm{mM}$ and from 5 to $80 \mathrm{mM}$, respectively.

\subsection{Analysis}

The treated water was analyzed immediately after the treatment. The concentrations of phenol and $\mathrm{H}_{2} \mathrm{O}_{2}$ were determined by colorimetric methods with a UV-Vis spectrometer (UVmini-1240, Shimadzu). The 4-aminoantipyrine and iodide methods (Allen et al., 1952; Kormann et al., 1988) were utilized for the analysis of 
109 phenol and $\mathrm{H}_{2} \mathrm{O}_{2}$ at $\lambda=507$ and $350 \mathrm{~nm}$, respectively. The total organic carbon (TOC)

110 concentration was measured using a TOC analyzer (TOC-V $\mathrm{V}_{\mathrm{CSH}}$, Shimadzu). The

111 quantitative measurement of organic acids was carried out by using a

112 non-suppressor-type ion chromatograph system equipped with a Shim-pack IC-A1

113 column (100 mm long). An aqueous solution of phthalic acid (2.5 $\mathrm{mM})$ and

114 tris(hydroxymethyl)aminomethane $(2.4 \mathrm{mM})$ was used as the mobile phase at a flow

115 rate of $1.5 \mathrm{~mL} \mathrm{~min}^{-1}$ under isocratic conditions. Prior to analysis, treatment using a

116 solid-phase extraction cartridge was performed in order to remove ferric ions from

117 organic acid because ferric ions interfere with the quantitative analysis of oxalic acids,

118 as is examined in Supplementary Material (SM).

\section{Results and discussion}

\subsection{Mineralization behavior of phenol during the degradation by Fenton reagent}

Phenol was degraded by more than $95 \%$ within a few minutes under the

conditions performed in this study. Therefore, the TOC concentration, which is directly

correlated to the degree of mineralization, is examined. Figure 1 shows the change of 
127 the $Y_{\text {TOC }}$ significantly decreased just after the reaction was initiated, and then decreased more gradually. Mineralization appeared to stagnate after 120 min in all cases. $C_{\mathrm{Fe}(\mathrm{II}), 0}$ affects the mineralization rate in the initial stage, however, it has little effect on the mineralization rate after $120 \mathrm{~min}$. About $60 \%$ of the carbon contained in the phenol remained in the water at $240 \mathrm{~min} . C_{\mathrm{H} 2 \mathrm{O} 2,0}$ had a similar effect on the mineralization behavior of phenol as $C_{\mathrm{Fe}(\mathrm{II}), 0}$ although the effect was more significant.

Next, the consumption of $\mathrm{H}_{2} \mathrm{O}_{2}$ during the treatment is examined. Figure 2 shows the change of the concentration of $\mathrm{H}_{2} \mathrm{O}_{2}, C_{\mathrm{H} 2 \mathrm{O} 2}$, as a function of time at various values of $C_{\mathrm{Fe}(\mathrm{II}), 0}$ and at $C_{\mathrm{H} 2 \mathrm{O} 2,0}=20 \mathrm{mM} . \mathrm{H}_{2} \mathrm{O}_{2}$ was rapidly consumed in the initial stage within $30 \mathrm{~min}$. This rapid consumption indicated that severe degradation occurred and terminated within 30 min. After 30 min, minimal $\mathrm{H}_{2} \mathrm{O}_{2}$ was consumed when $C_{\mathrm{Fe}(\mathrm{II}), 0}$ was less than $0.5 \mathrm{mM}$. On the other hand, $C_{\mathrm{H} 2 \mathrm{O} 2}$ gradually decreased when $C_{\mathrm{Fe}(\mathrm{II}), 0}$ was $1.0 \mathrm{mM} . C_{\mathrm{H} 2 \mathrm{O} 2}$ values at $240 \mathrm{~min}$ were $0.2,6.6$, and $10.4 \mathrm{mM}$ in the case of $1.0,0.5$, and $0.25 \mathrm{mM}$ of $C_{\mathrm{Fe}(\mathrm{II}), 0}$, respectively, whereas a significant difference was not observed in $Y_{\text {TOC }}$ values among the three cases. Stagnation of the mineralization after $120 \mathrm{~min}$ in the case of $C_{\mathrm{Fe}(\mathrm{II}), 0} \leq 0.5 \mathrm{mM}$ was not due to the depletion of $\mathrm{H}_{2} \mathrm{O}_{2}$ because sufficient $\mathrm{H}_{2} \mathrm{O}_{2}$ remained in the treated water. Therefore, the organic products, which are supposed to be organic acids, were analyzed to examine the influence of organic acids on the 
degradation by Fenton reagent.

\subsection{Formation behavior of oxalic acid}

Oxalic acid and formic acid could be quantified in the treated water in this study. Other organic acids such as acetic acid, glycolic acid, malonic acid, malic acid, and tartaric acid were also detected in the case of low $C_{\mathrm{Fe}(\mathrm{II}), 0}$, however, their yields, which were all less than $0.025 \mathrm{~g}-\mathrm{C} \mathrm{g-C^{-1 }}$, were too low to be quantified. Figure 3 shows the yields of oxalic acid $\left(Y_{\text {oxalic }}\right)$, formic acid $\left(Y_{\text {formic }}\right), Y_{\mathrm{TOC}}$, and $C_{\mathrm{H} 2 \mathrm{O} 2}$ as a function of $C_{\mathrm{Fe}(\mathrm{II}), 0}$ value in the degradation of phenol by Fenton reagent for $150 \mathrm{~min}$. The yield of organic acid was represented on a carbon basis, so that it could be compared with $Y_{\mathrm{TOC}}$ directly. $Y_{\text {oxalic }}$ was significantly dependent on $C_{\mathrm{Fe}(\mathrm{II}), 0}$. At $0.12 \mathrm{~g}-\mathrm{C} \mathrm{g}-\mathrm{C}^{-1}$, the $Y_{\text {oxalic }}$ corresponded to just $16 \%$ of the carbon remaining in the treated water when phenol was treated with $0.1 \mathrm{mM}$ of $C_{\mathrm{Fe}(\mathrm{II}), 0}$. It increased with the increase of $C_{\mathrm{Fe}(\mathrm{II}), 0}$, and reached as high as $0.55 \mathrm{~g}-\mathrm{C} \mathrm{g}-\mathrm{C}^{-1}$ when phenol was treated with $1.5 \mathrm{mM}$ of $C_{\mathrm{Fe}(\mathrm{II}), 0}$. The ratio of $Y_{\text {oxalic }}$ to $Y_{\text {TOC }}$ exceeded 0.8 , indicating that carbon remaining in the treated water almost existed as oxalic acid. It can be said that oxalic acid was preferentially formed at high $C_{\mathrm{Fe}(\mathrm{II}), 0}$ because $Y_{\mathrm{TOC}}$ of the degradation with $1.5 \mathrm{mM}$ of $C_{\mathrm{Fe}(\mathrm{II}), 0}$ was almost the same as that of the degradation with $0.3 \mathrm{mM}$ of $C_{\mathrm{Fe}(\mathrm{II}), 0}$ at $150 \mathrm{~min}$. The formation of formic acid 
was insignificant compared with oxalic acid and could not quantified in the case of $C_{\mathrm{Fe}(\mathrm{II}), 0} \geq 1.0 \mathrm{mM}$.

As for the formation profile of oxalic acid, a significant amount of oxalic acid was formed at the initial stage within $30 \mathrm{~min}$ and its yield appeared to be almost unchanged after 60 min under various values of $C_{\mathrm{Fe}(\mathrm{II}), 0}$ and $C_{\mathrm{H} 2 \mathrm{O} 2,0}$ (Fig. SM-1). These results related to the formation behavior of oxalic acid are consistent with the report of Zazo et al. (2007). Since the oxalic acid is not degraded by Fenton reagent solely, degradation proceeded slowly to decrease TOC concentration after $60 \mathrm{~min}$, as shown in Fig. $1.89 \%$ of the carbon contained in the phenol was converted to $\mathrm{CO}_{2}$ or oxalic acid at $150 \mathrm{~min}$ in the case of $C_{\mathrm{Fe}(\mathrm{II}), 0}=1.0 \mathrm{mM}$. It can be said that the degradation of organic compounds in the treated water almost went to completion in the case of $C_{\mathrm{Fe}(\mathrm{II}), 0}=1.0$ $\mathrm{mM}$ because oxalic acid is the final product of the degradation by Fenton reagent as well as $\mathrm{CO}_{2}$. On the other hand, the degradation seemed not to go to completion in the case of $C_{\mathrm{Fe}(\mathrm{II}), 0}=0.2 \mathrm{mM}$ because the sum of the yields of oxalic acid and $\mathrm{CO}_{2}$ is 0.47 $\mathrm{g}-\mathrm{C} \mathrm{g}-\mathrm{C}^{-1}$ at $150 \mathrm{~min}$.

\subsection{Effect of oxalic acid on the iron cycle in the water}

Degradation mainly proceeds by the formation of an active radical though the iron cycle between $\mathrm{Fe}(\mathrm{II})$ and Fe(III). The rate of the iron cycle is determined by the 
181 reduction rate of $\mathrm{Fe}(\mathrm{III})$ because the oxidation rate of $\mathrm{Fe}(\mathrm{II})$, Reaction (1), is very rapid.

182 Therefore, the reducing behavior of Fe(III) is examined here. required for oxalic acid formation when $C_{\mathrm{Fe}(\mathrm{II}), 0}$ is low. Thus, the degradation was performed for $24 \mathrm{~h}$ at various values of $C_{\mathrm{Fe}(\mathrm{II}), 0}$ and at $C_{\mathrm{H} 2 \mathrm{O} 2,0}=20 \mathrm{mM} . Y_{\mathrm{TOC}}, Y_{\text {oxalic, }}$, and

$\mathrm{C}_{\mathrm{H} 2 \mathrm{O} 2}$ at $24 \mathrm{~h}$ are shown in Fig. $4 . . \mathrm{H}_{2} \mathrm{O}_{2}$ was additionally dosed to be $20 \mathrm{mM}$ at $240 \mathrm{~min}$ only in the case of $C_{\mathrm{Fe}(\mathrm{II}), 0}=1.0 \mathrm{mM}$ because $\mathrm{H}_{2} \mathrm{O}_{2}$ was almost consumed. $Y_{\text {oxalic }}$ in the cases of $C_{\mathrm{Fe}(\mathrm{II}), 0}=0.2$ and $0.5 \mathrm{mM}$ showed minimal increase by extending the treatment time, and it was much lower than that for $C_{\mathrm{Fe}(\mathrm{II}), 0}=1.0 \mathrm{mM}$ at $150 \mathrm{~min}$, although a considerable amount of $\mathrm{H}_{2} \mathrm{O}_{2}$ remained in the treated water. These results clearly show that oxalic acid cannot be produced in the case of low $C_{\mathrm{Fe}(\mathrm{II}), 0}$ as much as it can in the case of high $C_{\mathrm{Fe}(\mathrm{II}), 0}$. Therefore, it is considered that $\mathrm{Fe}(\mathrm{III})$ is minimally reduced, in other word, the activity of $\mathrm{Fe}(\mathrm{III})$ is significantly lowered, during the degradation. It has been reported that the strong coordination of oxalic acids to ferric ions deactivates the degradation activity of ferric ions, as stated in the introduction. There is another possibility that the unidentified products are difficult to degrade by Fenton reagent, although Zazo et al. (2007) reported that they were the precursors of oxalic acid. 

the water treated with $0.2 \mathrm{mM}$ of $C_{\mathrm{Fe}(\mathrm{II}), 0}$ and the other was the comparison of $\mathrm{H}_{2} \mathrm{O}_{2}$ ion was additionally dosed in the water treated with $0.2 \mathrm{mM}$ of $C_{\mathrm{Fe}(\mathrm{II}), 0}$ for $24 \mathrm{~h}$ so that the concentration of total iron ions was $1.0 \mathrm{mM} . Y_{\mathrm{TOC}}, Y_{\mathrm{oxali}}$, and $C_{\mathrm{H} 2 \mathrm{O} 2}$ were measured 60 min after additional dosing at $24 \mathrm{~h}$, and the results are shown in Fig. 4. $Y_{\mathrm{TOC}}$

206 decreased significantly from 0.53 to $0.45 \mathrm{~g}-\mathrm{C} \mathrm{g-C}{ }^{-1}$ and $Y_{\text {oxalic }}$ reached $0.32 \mathrm{~g}-\mathrm{C} \mathrm{g}-\mathrm{C}^{-1}$.

207 Degradation was found to proceed significantly by the addition of ferric irons. This 208 result clearly indicates that the remaining organic compounds were degradable by 209 Fenton reagent and that the stagnation of the mineralization was due to the deactivation 210 of $\mathrm{Fe}(\mathrm{III})$. It was also confirmed that some of the unidentified products were the 211 precursors of oxalic acid. As for the comparison of $\mathrm{H}_{2} \mathrm{O}_{2}$ consumption rate, Fig. 5 212 compares the change of $C_{\mathrm{H} 2 \mathrm{O} 2}$ as a function of time in the water containing $1.0 \mathrm{mM}$ of $213 C_{\mathrm{Fe}(\mathrm{III})}$ with various concentrations of oxalic acid, $C_{\text {oxalic }} .80 \%$ of $\mathrm{H}_{2} \mathrm{O}_{2}$ was consumed in $214120 \mathrm{~min}$ when no oxalic acid was present in the water. In the case of $C_{\text {oxalic }}=0.5 \mathrm{mM}$, $215 \mathrm{H}_{2} \mathrm{O}_{2}$ was consumed as is the case with no oxalic acid whereas only $25 \%$ of $\mathrm{H}_{2} \mathrm{O}_{2}$ was consumed in the case of $C_{\text {oxalic }}=1 \mathrm{mM}$. When $C_{\text {oxalic }}$ was $1.5 \mathrm{mM}$, minimal $\mathrm{H}_{2} \mathrm{O}_{2}$ was 
217 consumed. Thus, the activity of $\mathrm{Fe}(\mathrm{III})$ is almost lost if the molar ratio of $C_{\text {oxalic }}$ to $C_{\mathrm{Fe}(\mathrm{III})}$

218 exceed 1.5 in the absence of reducing agent.

The consumption behavior of $\mathrm{H}_{2} \mathrm{O}_{2}$ shown in Fig. 2 is examined here. $\mathrm{H}_{2} \mathrm{O}_{2}$

was more rapidly consumed in the initial stage within 30 min compared with the case in

which there was no oxalic acid, as shown in Fig. 5. This is because the reduction of

$\mathrm{Fe}(\mathrm{III})$ occurred not only by $\mathrm{H}_{2} \mathrm{O}_{2}$ but also by the degradation products. In this initial stage, a considerable amount of oxalic acid is produced to deactivate Fe(III). The

$0.5 \mathrm{mM}$ because the molar ratio of $C_{\text {oxalic }}$ to $C_{\mathrm{Fe}(\mathrm{III})}$ had already exceeded 2 . Therefore,

226 the yield of oxalic acid is dependent on the $C_{\mathrm{Fe}(\mathrm{II}), 0}$. On the other hand, in the case of

$227 C_{\mathrm{Fe}(\mathrm{II}), 0}=1.0 \mathrm{mM}, \mathrm{H}_{2} \mathrm{O}_{2}$ was gradually consumed. Organic intermediates in the water

228 may act as reducing agents for $\mathrm{Fe}(\mathrm{III})$, because the molar ratio of $C_{\text {oxalic }}$ to $C_{\mathrm{Fe}(\mathrm{III})}$ was

229 1.5. Stagnation of mineralization was observed after $120 \mathrm{~min}$ in both cases, as shown in

230 Fig. 1, but the situation was different in those cases. In the former case, Fe(III) was

231 minimally reduced by the coordination of oxalic acid although a fairly large amount of

$232 \mathrm{H}_{2} \mathrm{O}_{2}$ and degradable organic compounds remained in the water. In the latter case, the conversion to oxalic acid, although reduction of Fe(III) occurred slowly. 
words, to reduce $Y_{\text {TOC. }}$ Figure 4 helps us to examine the conditions that reduce $Y_{\text {TOC. }}$ At

$24 \mathrm{~h}$, the degradation with $0.5 \mathrm{mM}$ of $C_{\mathrm{Fe}(\mathrm{II}), 0}$ gave lower $Y_{\mathrm{TOC}}$ compared to that with 1.0 $\mathrm{mM}$ of $C_{\mathrm{Fe}(\mathrm{II}), 0}$. In the case of $C_{\mathrm{Fe}(\mathrm{II}), 0}=1.0 \mathrm{mM}, Y_{\mathrm{TOC}}$ was reduced only slightly with the prolonged treatment because a large part of organic compounds is oxalic acid even at $150 \mathrm{~min}$. As a result, 97\% of the remaining carbon was oxalic acid at $24 \mathrm{~h}$ because

$242 Y_{\text {oxalic }} / Y_{\mathrm{TOC}}=0.97$. On the other hand, the organic compounds that can be mineralized 243 remained in the degradation with $0.5 \mathrm{mM}$ of $C_{\mathrm{Fe}(\mathrm{II}), 0}$ at $150 \mathrm{~min}$. Therefore, $Y_{\mathrm{TOC}}$ could 244 be reduced from 0.63 to $0.47 \mathrm{~g}-\mathrm{C} \mathrm{g}_{-} \mathrm{C}^{-1}$ by prolonged treatment, although the 245 mineralization rate was very slow. From these results, $Y_{\mathrm{TOC}}$ can be reduced if the 246 degradation is allowed to proceed with a lower concentration of oxalic acid. To achieve 247 this situation, ferrous ion was supplied in intermittent doses. The same amount of 248 ferrous ion was dosed every 120 min a total of four times so that the total concentration 249 of iron ions was $1.0 \mathrm{mM}$. $C_{\mathrm{H} 2 \mathrm{O} 2,0}$ was $40 \mathrm{mM}$. Figure 6 shows the $Y_{\mathrm{TOC}}, Y_{\text {oxalic }}$, and $250 C_{\mathrm{H} 2 \mathrm{O} 2}$ at $480 \mathrm{~min}$. Four intermittent doses were effective in enhancing the degree of 251 mineralization. $Y_{\mathrm{TOC}}$ in the case of four intermittent dosing was significantly reduced to $2520.39 \mathrm{~g}-\mathrm{C} \mathrm{g}-\mathrm{C}^{-1}$, whereas that in the case of all-at-once dosing was $0.53 \mathrm{~g}-\mathrm{C} \mathrm{g}-\mathrm{C}^{-1}$, 
253 although the consumption of $\mathrm{H}_{2} \mathrm{O}_{2}$ was almost the same in both cases. The formation of

254 oxalic acid was also suppressed by four intermittent dosing as expected. Phenol was

255 eventually converted to $\mathrm{CO}_{2}$ or oxalic acid through the unidentified products during the

256 degradation by Fenton reagent. It was found that intermittent dosing was effective for

257 converting the unidentified products to $\mathrm{CO}_{2}$ preferentially. Thus, the mineralization

258 degree could be enhanced by employing intermittent dosing using same amount of

259 Fenton reagent.

\section{Conclusions}

In this study, the influence of oxalic acid on the degradation of phenol by

263 Fenton reagent was examined. Oxalic acid formed during the degradation was found to

264 suppress the reduction of ferric ions by coordination, terminating the degradation

265 reaction in the initial stage within $30 \mathrm{~min}$. Since the minimal amount of oxalic acid was

266 formed after the degradation reaction terminated, the yield of oxalic acid was dependent

267 on the amount of ferrous ion dosed. Mineralization of phenol by Fenton reagent stagnated after 120 min under the conditions used in this study. The reason why the mineralization stagnated was assumed as follows: In the case where a small amount of ferrous ions was dosed, the reduction of ferric ions was minimal by oxalic acid formed, 
271 although a fairly large amount of $\mathrm{H}_{2} \mathrm{O}_{2}$ and degradable organic compounds remained in

272 the water. The fact that the degradation proceeded significantly by dosing additional

273 ferric ions to the treated water supports this result. In the case where a large amount of

274 ferrous ions was dosed, the amount of degradable organic compounds was insufficient

275 owing to preferential conversion to oxalic acid, although $\mathrm{H}_{2} \mathrm{O}_{2}$ was gradually consumed.

276 Phenol was eventually converted to $\mathrm{CO}_{2}$ or oxalic acid through the unidentified

277 products during the degradation by Fenton reagent. Therefore, it was inferred that TOC

278 can be reduced significantly if the degradation is allowed to proceed with a lower

279 concentration of oxalic acid. A same amount of ferrous ion was supplied in four

280 intermittent doses for this purpose. TOC yield could be reduced by $26 \%$ compared to

281 the degradation with all-at-once dose when the same amounts of ferrous ion and $\mathrm{H}_{2} \mathrm{O}_{2}$

282 were used. The yield of oxalic acid was also suppressed by intermittent dosing as expected. These results indicated that intermittent dosing of ferrous ion was effective for converting phenol to $\mathrm{CO}_{2}$ rather than oxalic acid through the unidentified degradation products.

This work was partially supported by Japan Society for the Promotion of Science 
289 (JSPS), Grant-in-Aid for Challenging Exploratory Research 22656182.

290 
291

292

293

294

295

296

297

298

299

300

References

Allen, A.O., Hochanadel, C.J., Ghormley, J.A., Davis, T.W., 1952. Decomposition of water and aqueous solutions under mixed fast neutron and gamma radiation. J. Phys. Chem. 56, 575-586.

Andreozzi, R., Caprio, V., Insola, A., Marotta, R., 1999. Advanced oxidation processes (AOPs) for water purification and recovery. Catal. Today 53, 51-59.

Barb, W.G., Baxendale, J.H., George, P., Hargrave, K.R., 1951a. Reactions of ferrous and ferric ions with hydrogen peroxide. Part I. -The ferrous ion reaction. Trans. Faraday Soc. 47, 462-500.

Barb, W.G., Baxendale, J.H., George, P., Hargrave, K.R., 1951b. Reactions of ferrous and ferric ions with hydrogen peroxide. Part II. -The ferric ion reaction. Trans. Faraday Soc. 47, 591-616.

Bautista, P., Mohedano, A.F., Casas, J.A., Zazo, J.A., Rodriguez, J.J., 2008. An overview of the application of Fenton oxidation to industrial wastewaters treatment. J. Chem. Technol. Biotechnol. 83, 1323-1338.

Bigda, R.J., 1995. Consider Fenton's chemistry for wastewater treatment. Chem. Eng. Prog. 91, 62-66.

Chamarro, E., Marco, A., Esplugas, S., 2001. Use of Fenton reagent to improve organic 
chemical biodegrability. Water Res. 35, 1047-1051.

Chen, R., Pignatello, J., 1997. Role of quinine intermediates as electron shuttles in Fenton and photo-assisted Fenton oxidation of aromatic compounds. Environ. Sci. Technol. 31, 2399-2406.

Harber, F., Weiss, J.J., 1934. The catalytic decomposition of hydrogen peroxide by iron salts. Proc. Roy. Soc. London Ser. A 147, 332-345. and monochlorophenols. Chemosphere 47, 915-924. oxidation by Fenton reagent. Environ. Sci. Technol. 40, 5538-5543.

Kormann, C., Bahnemann, D.W., Hoffmann, M.R., 1988. Photocatalytic production of $\mathrm{H}_{2} \mathrm{O}_{2}$ and organic peroxides in aqueous suspensions of $\mathrm{TiO}_{2}, \mathrm{ZnO}$, and desert sand. Environ. Sci. Technol. 22, 798-806.

Kwon, B.G., Lee, D.S., Kang, N., Yoon, J., 1999. Characteristics of p-chlorophenol oxidation by Fenton's reagent. Water Res. 33, 2110-2118.

Lopez, A., Pagano, M., Volpe, A., Pinto, A.C.D., 2004. Fenton's pre-treatment of mature landfill leachate. Chemosphere 54, 1005-1010.

Mijangos, F., Varona, F., Villota, N., 2006. Changes in solution color during phenol 5

Sun, Y., Pignatello, J.J., 1992. Chemical treatment of pesticide wastes. Evaluation of 
$\mathrm{Fe}(\mathrm{III})$ chelates for catalytic hydrogen peroxide oxidation of $2,4-\mathrm{D}$ at circumneutral pH. J. Agric. Food Chem. 40, 322-327.

Sun, Y., Pignatello, J.J., 1993. Organic intermediates in the degradation of 2,4-dichlorophenoxyacetic acid by $\mathrm{Fe}^{3+} / \mathrm{H}_{2} \mathrm{O}_{2}$ and $\mathrm{Fe}^{3+} / \mathrm{H}_{2} \mathrm{O}_{2} /$ UV. J. Agr. Food Chem. 41, 1139-1142.

Tamagaki, S., Suzuki, K., Tagaki, W., 1989a. Aromatic hydroxylation with an iron(III)-catechol- $\mathrm{H}_{2} \mathrm{O}_{2}$ system. Bull. Chem. Soc. Jpn. 62, 148-152.

Tamagaki, S., Sasaki, M., Tagaki, W., 1989b. Fe(III)-catalyzed aromatic hydroxylation with $\mathrm{H}_{2} \mathrm{O}_{2}$ in the presence of variety of electron-transfer agents. Bull. Chem. Soc. Jpn. 62, 153-158.

Wadley, S., Waite, T.D., 2004. Fenton Processes. in: Parsons S. (Ed.), Advanced Oxidation Processes for Water and Wastewater Treatment, IWA publishing, London, pp.111-136.

Walling, C., 1975. Fenton's reagent revisited. Account Chem. Res. 8, 125-131.

Zazo, J.A., Casas, J.A., Mohedano, A.F., Gilarranz, M.A., Rodriguez, J.J., 2005. Chemical pathway and kinetics of phenol oxidation by Fenton's reagent. Environ. Sci. Technol. 39, 9295-9302.

Zazo, J.A., Casas, J.A., Molina C.B., Quintanilla, A., Rodriguez, J.J., 2007. Evolution 
of ecotoxicity upon Fenton's oxidation of phenol in water. Environ. Sci. Technol.

346 41, 7164-7170.

347

Zimbron, J.A., Reardon, K.F., 2009. Fenton's oxidation of pentachlorophenol. Water

348 Res. 43, 1831-1840.

349 
350

Figure Captions

Fig. 1. The change of the TOC concentration against treatment time during the degradation of phenol by Fenton reagent when (a) $C_{\mathrm{Fe}(\mathrm{II}), 0}$ was varied. (b) $C_{\mathrm{H} 2 \mathrm{O} 2}$ was varied.

Fig. 2. The change of the concentration of $\mathrm{H}_{2} \mathrm{O}_{2}$ as a function of time during the degradation of phenol by Fenton reagent when $C_{\mathrm{Fe}(\mathrm{II}), 0}$ was varied.

Fig. 3. The yields of oxalic acid, formic acid, $Y_{\mathrm{TOC}}$, and $C_{\mathrm{H} 2 \mathrm{O} 2}$ as a function of $C_{\mathrm{Fe}(\mathrm{II}), 0}$ value during the degradation of phenol by Fenton reagent for $150 \mathrm{~min}$.

Fig. 4. $Y_{\mathrm{TOC}}, Y_{\mathrm{oxalic}}$, and $C_{\mathrm{H} 2 \mathrm{O} 2}$ in the prolonged degradation when $C_{\mathrm{Fe}(\mathrm{II}), 0}$ was $0.2,0.5$, and $1.0 \mathrm{mM}$.

Fig. 5. Comparison of the change of $C_{\mathrm{H} 2 \mathrm{O} 2}$ as a function of time in the water containing $1.0 \mathrm{mM}$ of $C_{\mathrm{Fe}(\mathrm{III})}$ with various concentrations of oxalic acid.

Fig. 6. Comparison of the $Y_{\mathrm{TOC}}, Y_{\mathrm{oxalic}}$, and $\mathrm{C}_{\mathrm{H} 2 \mathrm{O} 2}$ at $480 \mathrm{~min}$ between four intermittent doses and all-at-once dose of $\mathrm{Fe}^{2+}$ when the same amounts of $\mathrm{Fe}^{2+}$ and $\mathrm{H}_{2} \mathrm{O}_{2}$ were dosed. 

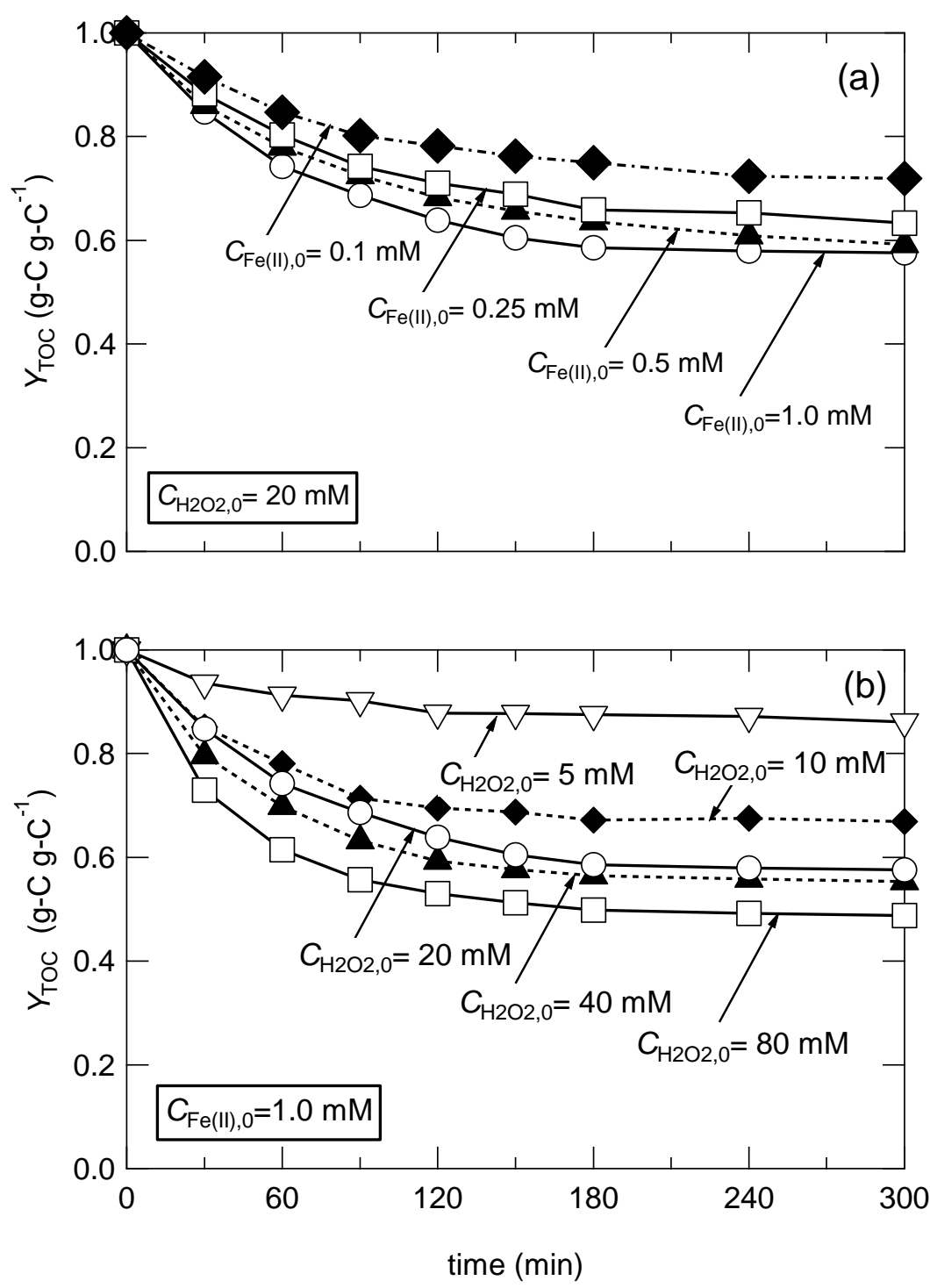

Fig. 1 The change of the TOC concentration against treatment time during the degradation of phenol by Fenton reagent when (a) $C_{\mathrm{Fe}(\mathrm{II}), 0}$ was varied. (b) $C_{\mathrm{H} 2 \mathrm{O} 2}$ was varied. 


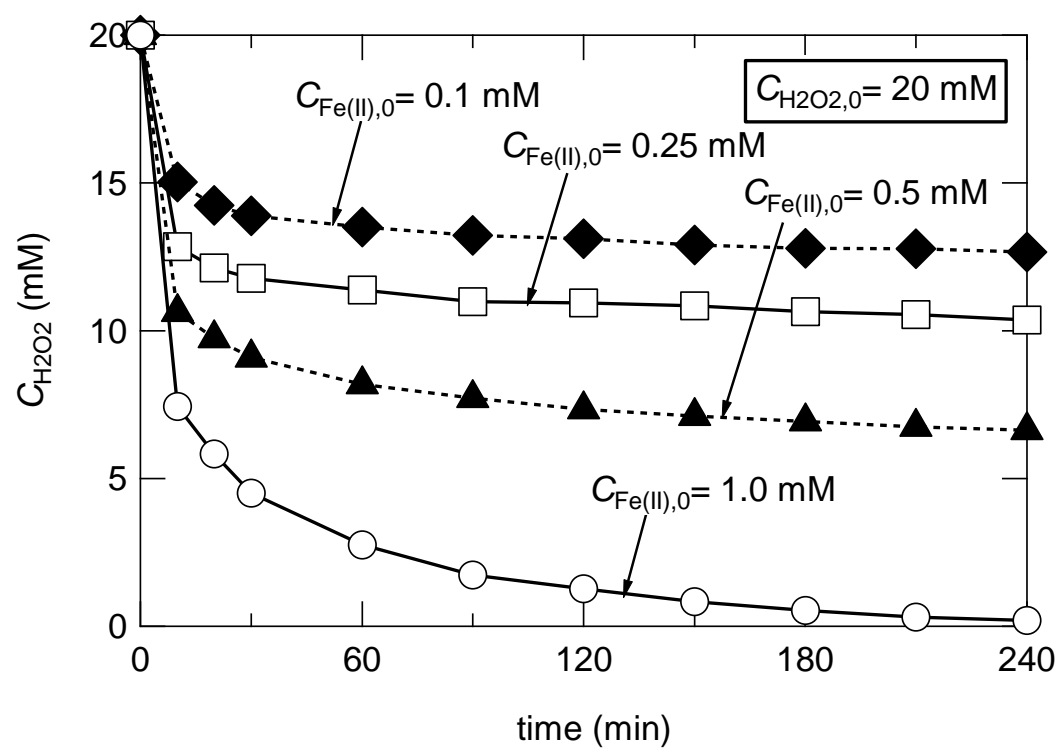

380

Fig. 2 The change of the concentration of $\mathrm{H}_{2} \mathrm{O}_{2}$ as a function of time during the 382 degradation of phenol by Fenton reagent when $C_{\mathrm{Fe}(\mathrm{II}), 0}$ was varied. 


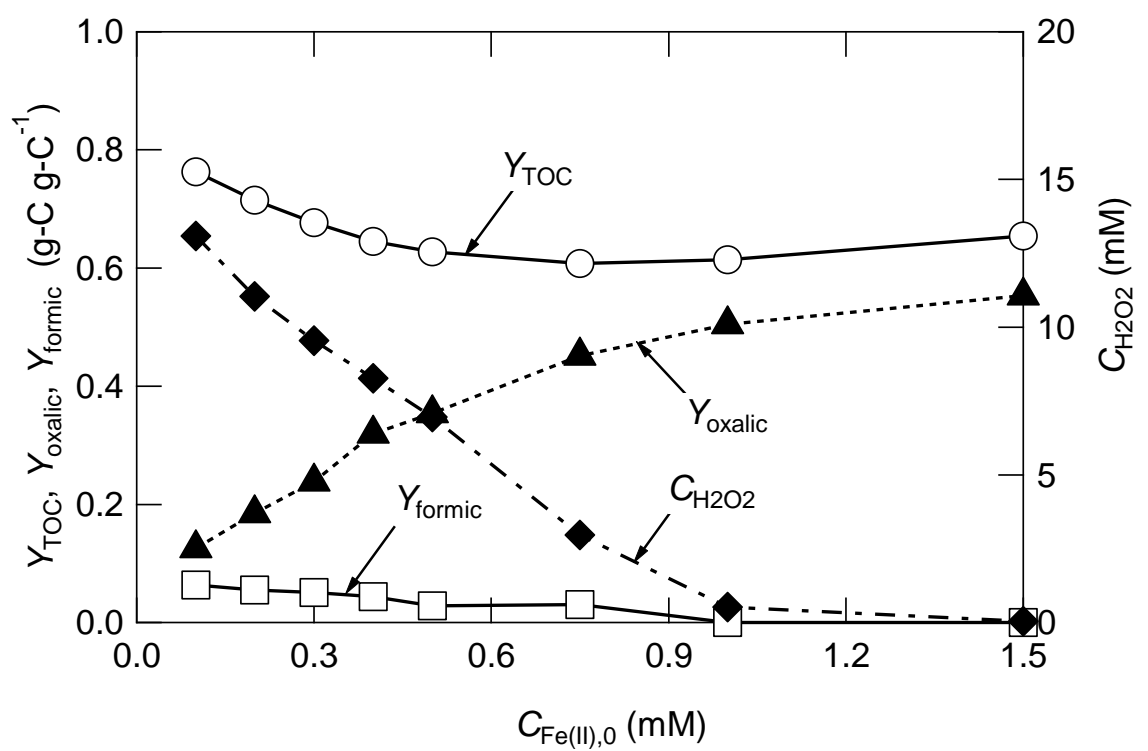

Fig. 3 The yields of oxalic acid, formic acid, $Y_{\mathrm{TOC}}$, and $C_{\mathrm{H} 2 \mathrm{O} 2}$ as a function of $C_{\mathrm{Fe}(\mathrm{II}), 0}$ value during the degradation of phenol by Fenton reagent for $150 \mathrm{~min}$.

388 


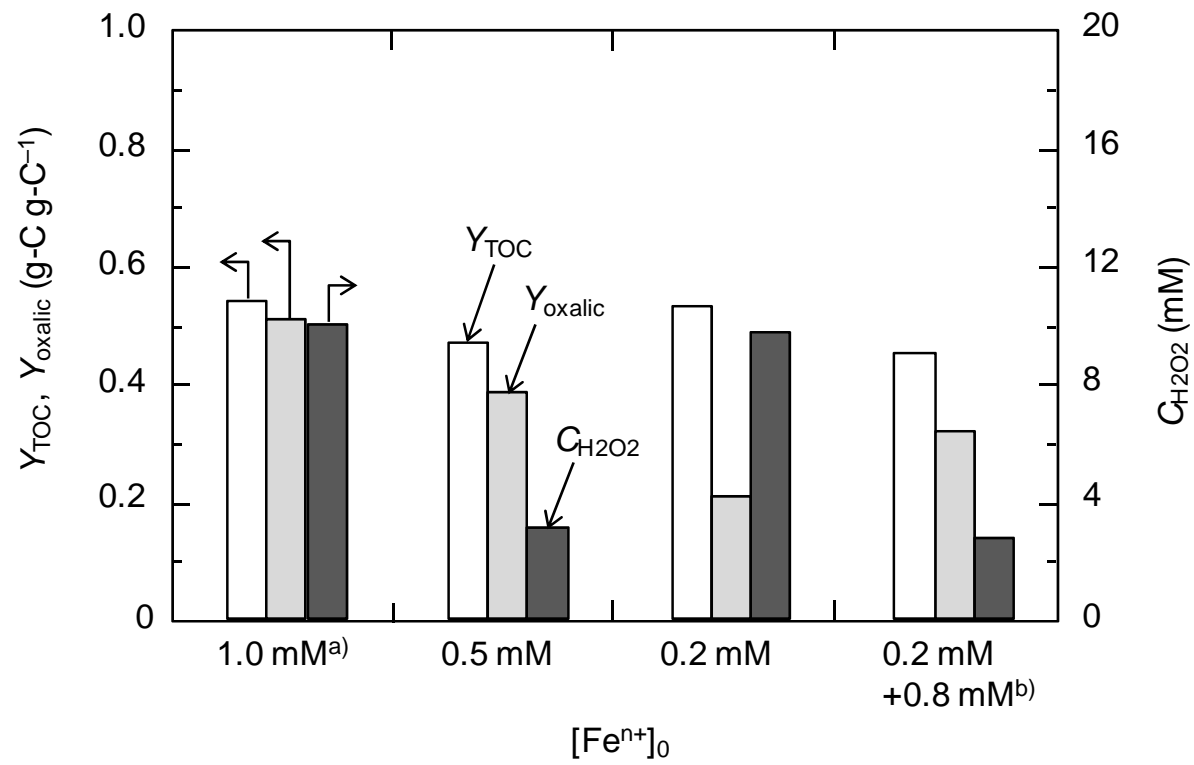

a) $\mathrm{H}_{2} \mathrm{O}_{2}$ was additionally dosed at $240 \mathrm{~min}$ to be $20 \mathrm{mM}$ because $\mathrm{H}_{2} \mathrm{O}_{2}$ was almost consumed.

b) $\mathrm{Fe}^{3+}$ was dosed to the water treated with $0.2 \mathrm{mM}$ of $C_{\mathrm{Fe}(\mathrm{II}), 0}$ at $24 \mathrm{~h}$ so that the total amount of ion ions dosed was same as that of treated with $1.0 \mathrm{mM}$ of $C_{\mathrm{Fe}(I I), 0}$.

Fig. $4 Y_{\mathrm{TOC}}, Y_{\text {oxalic }}$, and $C_{\mathrm{H} 2 \mathrm{O} 2}$ in the prolonged degradation when $C_{\mathrm{Fe}(\mathrm{II}), 0}$ was $0.2,0.5$, and $1.0 \mathrm{mM}$. 


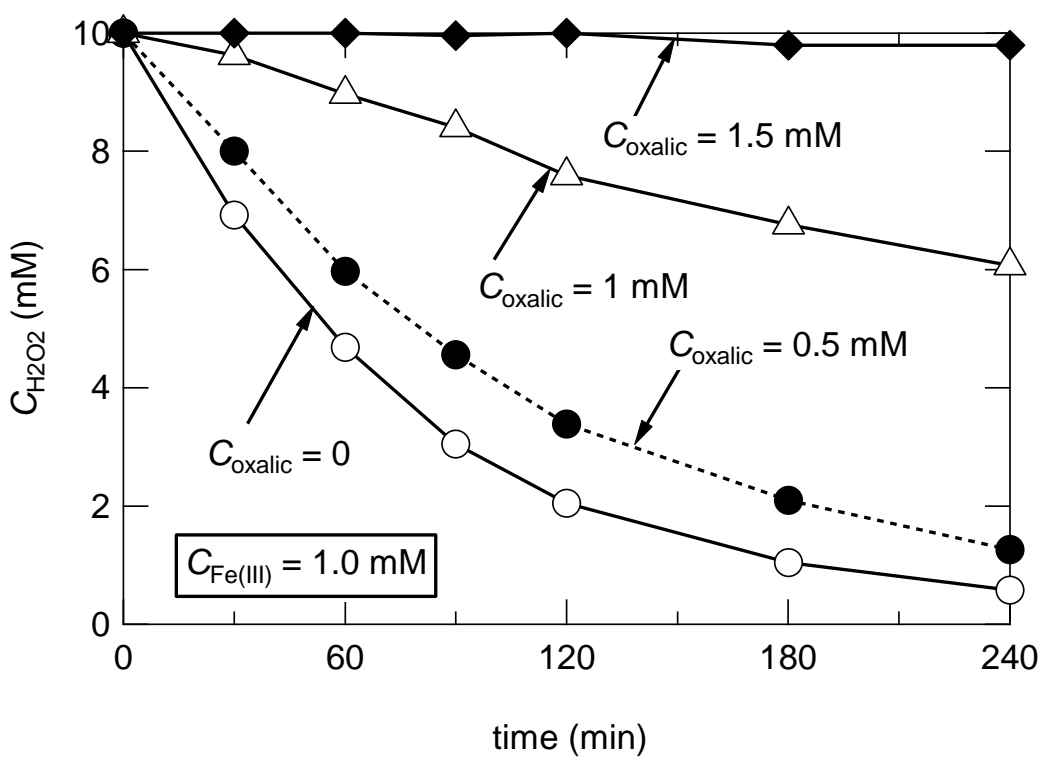

395

Fig. 5 Comparison of the change of $\mathrm{C}_{\mathrm{H} 2 \mathrm{O} 2}$ as a function of time in the water containing 397 $1.0 \mathrm{mM}$ of $C_{\mathrm{Fe}(\mathrm{III})}$ with various concentrations of oxalic acid.

398 


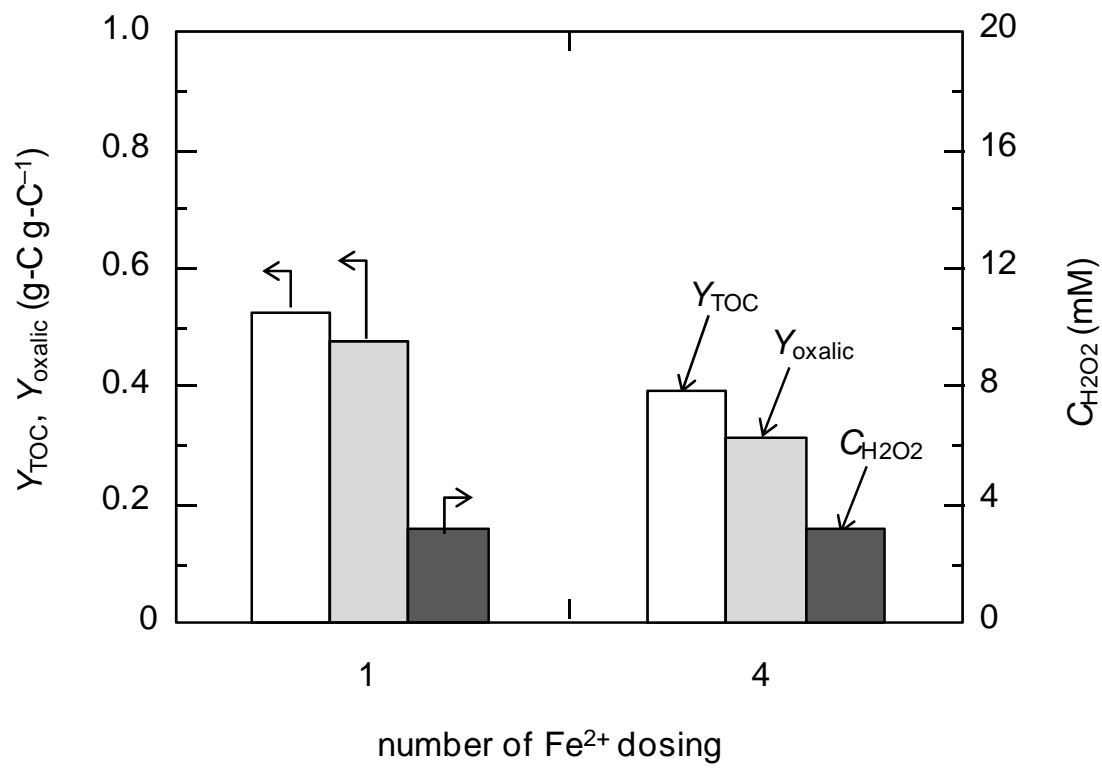

400

401 Fig. 6 Comparison of the $Y_{\mathrm{TOC}}, Y_{\text {oxalic }}$, and $C_{\mathrm{H} 2 \mathrm{O} 2}$ at 480 min between four intermittent doses and all-at-once dose of $\mathrm{Fe}^{2+}$ when the same amounts of $\mathrm{Fe}^{2+}$ and $\mathrm{H}_{2} \mathrm{O}_{2}$ were dosed. 